\title{
The Role of Cloud Computing in Education: Saudi Arabian Study
}

\author{
https://doi.org/10.3991/ijim.v15i24.27363
}

\author{
Gareebah Al-Rasheedi, Nabeel Khan ${ }^{(\varpi)}$ \\ Qassim University, Buraydah, Saudi Arabia \\ n.khan@qu.edu.sa
}

\begin{abstract}
Education is a crucial factor in ensuring sustainable progress, In particular, for countries with growing economies. Due to resource virtualization, Cloud computing has both the Internet and complex scalability. Both public and private learning institutions should take advantage of the potential benefit of cloud infrastructure to ensure high-quality service regardless of the minimum resources available. Cloud computing is gaining popularity in academia due to its numerous benefits. This study will attempt to determine the advantages of using cloud computing in education. Cloud technology solutions improve the sustainability and efficiency of research and development as well as teaching, thereby improving the quality of teaching and learning in educational institutions. The goal of this research is to identify the benefits of cloud computing usage in education. Cloud technology solutions make research and development as well as teaching more competitive and effective, thereby having a positive impact on the quality of education.
\end{abstract}

Keywords—cloud computing, PaaS, IaaS, SaaS

\section{Introduction}

Education is vital to our well-being because it provides us with the tools, we need to achieve our goals. The usage of cloud computing is a powerful educational paradigm. The term "cloud computing" refers to a sort of internet-based computing that makes use of shared resources and data to benefit its users. For the first time in computing history, the cloud is a new way to use computing resources that can be divided up symbolically and traded back and forth between service providers. Network servers, applications, platforms, infrastructure parts, and services can all be considered as sources of resources. Because of its self-service nature, cloud computing can supply services on-demand while also providing suitable network connectivity, data resource environment, and flexible scalability. This breakthrough is used to centralize storage, memory, and computational capability on PCs and servers, making computing more efficient and cost-effective. We expect cloud computing to have a huge impact on education because of all the advantages it offers. Higher education institutions can be more adaptable thanks to cloud computing solutions. For institutions with dynamic demands, the cloud platform in campuses provides an efficient infrastructure and deployment architecture. 
That's advantageous. Using cloud computing in education can help with issues like cost reduction, quick and effective communication, security, privacy, and adaptability that are frequent in educational institutions. The authors of this report set out to uncover the advantages of cloud computing in Saudi Arabia's education sector. For our research, we look at how academic institutions might benefit from cloud computing not only financially but also operationally and qualitatively such as in terms of mobility and security. We also discussed cloud computing-related concerns in academia. The rest of the paper is organized as follows: in Section 2, we look at the current situation of education in Saudi Arabia and the problem statement. We give a brief overview of cloud computing and discuss the educational cloud computing environment. Section 3 mentions research methodology associated in accomplishing this research. Section 4 outlines results and discussions. Finally, section 5 concludes the paper followed by references [1].

\section{Related work and problem statement}

Cloud computing is the concept of pooling technological resources in the virtual world over the internet. Cloud computing. This phrase was coined by Google in 2006 and has now achieved common usage in today's technological world. Any individual or corporation can pay-per-use a series of services according to their specific needs with low management effort by putting online resources (Networks, servers, storage, and applications, for example) in a common pool. There are numerous advantages of cloud computing, such as scalability, cost-effectiveness, resiliency, service orientation, and agility, to name just a few. The cloud models' pay-per-use feature allows users to access the shared-pool online resources on the network to access the resources they need. End users can use a variety of devices, such as laptops, desktops, and smartphones, to access resources 24 hours a day, seven days a week, from anywhere. These are the platforms (System Software) and infrastructure (Hardware) that users access and employ online on-demand to execute various application software.as follows in Figure 1. [1] [2-6] the Models of Cloud Deployment:

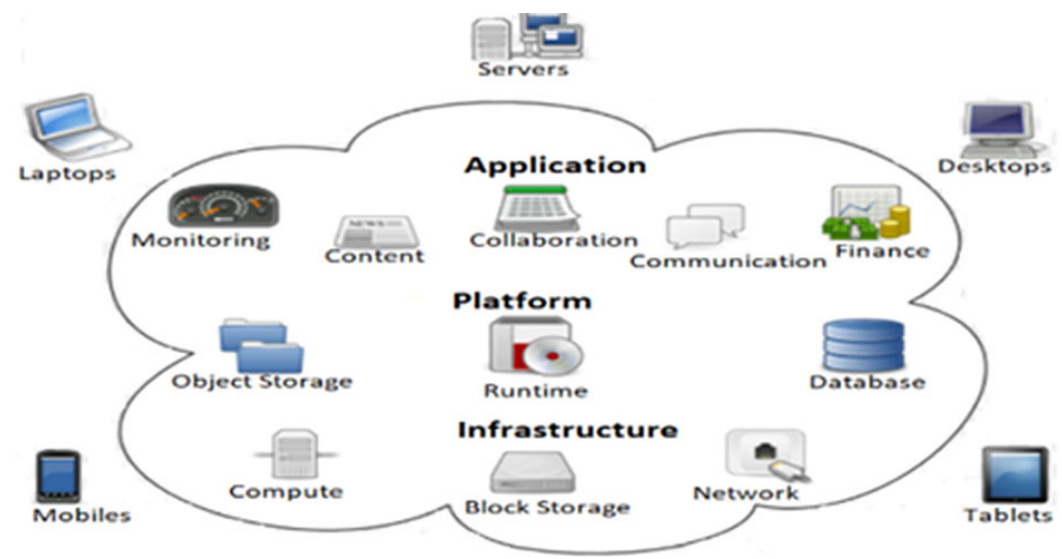

Fig. 1. Cloud computing 
There are four types of deployment models which are as follows in Figure 2:

a) Private Cloud

b) Hybrid Cloud

c) Public Cloud

d) Community Cloud. [7][8]

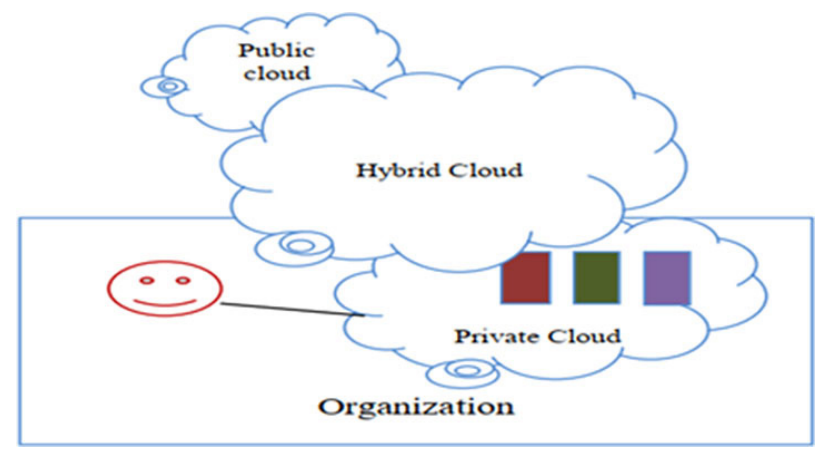

Fig. 2. Cloud deployment models

Cloud Service Models:

When it comes to cloud computing's many advantages and relevance, there are also many risks and security concerns, such as data leaking or loss or hacker attacks or malicious insiders. The National Institute of Standards and Technology (NIST) has described the following service models as having three categories [9][10]:

a) Infrastructure as a Service (IaaS): IaaS is all about virtual machine provisioning and operation Systems or networks of end-users.

b) Software as a service (SaaS): In this type of scenario, the user uses applications only Provided by the vendor, and these applications run on cloud services.

c) Platform as a Service (PaaS): In PaaS, the customer can configure what they want Application using some associated programming languages and libraries.

Applications for Cloud Computing in Education:

The internet has been a backbone of cloud computing offering variety of services for educational purposes. In lieu revolutionizing the concept and delivery of education. The application ecosystem of Cloud computing provides a direct access to a wide range of educational tools like ready to go platforms, research application, cloud based academic resources, etc. The major cloud service providers to educational institutes are Google, Amazon, Microsoft. etc.

Microsoft's initiative in making education more interactive and interesting has enabled services like Microsoft Windows Azure, Microsoft Live@edu, etc. Microsoft Live@edu is mainly considered for purposes related to education. Also, all services offer Larger financial flexibility for education and institutions, enabling lower costs of developing, scaling, operating, and migrating existing systems distributed between the cloud and the data center. Microsoft is taking steps in making workplace more 
functional and interoperable across all forms of devices from desktop computers to PDAs enabling students and researchers more productive and efficient. The following are some characteristics of Microsoft Live@edu. [11][12]:

a) Create websites

b) Share files

c) Word processing and presentation

d) File storage

e) Resource scheduling

f) Voice over Internet Protocol

g) Share resources like files and desktops.

Google Education Cloud:

Google Apps Education (GAE) in cloud computing is focused more on group specific tasks for colleges and universities. Google's (GAE) is incurs nominal fee for its subscribers to avail these services. [13] GAE includes the following applications:

Google Mail: The most widely used mail app used by enterprises and private users like students and researchers is Google Mail, similarly called Gmail, which is managing emails for enterprise IT administrator in the organization and universities. It has 7 $\mathrm{GB}$ of storing space for each user.

Google Talk: Also known as Gtalk, is the component of Google Apps related to instant messaging (IM). This IM platform is efficient in connecting people who are scattered on different remote locations.

Google Sites: This tool is mainly created to make web publishing more creative and hassle free for students to forge their technical skills. It is a student-friendly web publishing software makes it easier for them to develop their technical skills and post material and media without learning any programming languages.

Google Calendar: is a shared calendar management system that organizes schedules by putting everyone on campus "on the same page". Google Educational applications are widely using the following characteristics [14]:

a) Customizable: google apps is user friendly platform enabling users to set up different security settings, features options, and account permissions. Google apps assists institutions needs by monitoring student's actions such as turning email off for fourth graders, allowing first graders to email classmates.

b) Usable on any device: Because Google Apps are cutting-edge, they should function smoothly on a wide range of devices, including laptops, desktops, iPads, and Android tablets.

c) Free: To help educational institutions, Google offers a variety of free educational applications, including a teacher training center with video tutorials and telephone and email support.

d) Collaborative: For seamless teamwork google created collaboration Google Applications. They provide a solid foundation for collaboration, real-time editing, sharing controls, and interoperability. 
Amazon Education Cloud: The Amazon Education Cloud has given a web services platform for educational institutions of various sizes. There are a lot of customizable IT infrastructure services available to educational applications on AWS that can be requested by students or researchers and instructors. Also, flexibility is provided by this AWS model for researchers and faculty to opt for any service or development model. AWS provides a variety of educational institutions benefits, IT organizations, and developers alike as the following [12][15]:

a) Flexible: To make applications and resource controlling compatible to any application using any platform regardless of programming model, a boot space size is offered, selection of memory configuration and instance storage for the selection of the application and the operating system are some of the ways to make AWS functioning more flexible.

b) Secure: Amazon provides a secure environment for storing data.

c) Dependable: The Amazon Web Services (AWS) cloud is decentralized and infinitely expandable. Also, its secure, resilient and reliable by far as compared to competitors.

Comprehensive: The AWS offers large variety of services to its users to make it user friendly. Thus, encouraging them to be extra productive and progressive by developing applications and incorporating them in their researches and studies. [7,16].

Each new technology can contain problems that, with the advent of cloud computing in the Kingdom of Saudi Arabia, restrict the usage of new technology. The obstacle to embracing cloud computing starts with several problems. Security, privacy, and availability are the major concerns. This paper will discuss the cloud computing benefits. Educational technology to be introduced in the Kingdom of Saudi Arabia and to encourage the use and growth of cloud technology.

\section{$3 \quad$ Research methodology}

After researching the role and influence of cloud computing especially in education in many leading digital libraries such as IEEE Xplore, Semantic Researcher, and SpringerLink published between 2015 and 2020 Libraries. By using different terms and keywords such as cloud computing, education, and Saudi Arabia. I have found several findings in Saudi Arabia that concentrate on the role and effect of cloud computing on education. Centered on the detailed review proceeding, which concentrated on the implications of previous observations from a critical analysis of the literature that are summarized below in Table 1 . 
Table 1. Critical analysis of literature

\begin{tabular}{|c|c|c|}
\hline Aim & Methodology & Results \\
\hline $\begin{array}{l}\text { Regarding [10]: In this work } \\
\text { the authors presented a hybrid } \\
\text { cloud model is presented to } \\
\text { share the intellectual data of } \\
\text { all universities in KSA. Under } \\
\text { Saudi Arabia's Ministry of } \\
\text { Higher Education, the proposed } \\
\text { hybrid approach is workable. } \\
\text { The model's various elements } \\
\text { have been discussed, and the } \\
\text { model's efficacy has been } \\
\text { demonstrated. }\end{array}$ & $\begin{array}{l}\text { The proposed model is useful } \\
\text { in sharing the activities of } \\
\text { knowledge and research of the } \\
\text { universities in Saudi Arabia. In } \\
\text { Saudi Arabia, the Saudi Ministry } \\
\text { of Higher Education (MOHE) } \\
\text { can better manage and monitor } \\
\text { the country's higher education } \\
\text { institutions with the help of a } \\
\text { hybrid cloud architecture. MOHE } \\
\text { cloud is the ministry's public } \\
\text { cloud, which contains intellectual } \\
\text { capital data generated by } \\
\text { universities. }\end{array}$ & $\begin{array}{l}\text { If implemented in MOHE of } \\
\text { Saudi Arabia, it shall provide } \\
\text { all the required information } \\
\text { statistics that would help the } \\
\text { Ministry of Higher Education } \\
\text { (MOHE) keep track of and align } \\
\text { all higher education institutions } \\
\text { with the norms and rules it } \\
\text { sets. This concept will save the } \\
\text { government a significant amount } \\
\text { of money by eliminating the } \\
\text { need to purchase research and } \\
\text { higher education institutions' } \\
\text { hardware, software, networking, } \\
\text { and communication devices.. }\end{array}$ \\
\hline $\begin{array}{l}\text { According to [12]: This report } \\
\text { analyzed the present state of CC } \\
\text { adoption in the higher education } \\
\text { business to deepen the research } \\
\text { in this area of interest. Present } \\
\text { shortcomings and knowledge } \\
\text { gaps are established in current } \\
\text { empirical studies. In addition, } \\
\text { for the benefit of other } \\
\text { researchers who are interested } \\
\text { in this subject, suggested } \\
\text { areas for further research } \\
\text { will be highlighted. These } \\
\text { studies encourage educational } \\
\text { institutions to implement } \\
\text { cloud computing technology, } \\
\text { especially in higher education. }\end{array}$ & $\begin{array}{l}\text { Investigating several 2014-2017 } \\
\text { papers in a number of well- } \\
\text { known digital repositories as } \\
\text { IEEE Xplore, ScienceDirect, and } \\
\text { SpringerLink. }\end{array}$ & $\begin{array}{l}\text { Despite the fact that cloud } \\
\text { computing is becoming more } \\
\text { popular in higher education } \\
\text { institutions, several issues } \\
\text { still need to be addressed. } \\
\text { The critical, in-depth } \\
\text { review of existing empirical } \\
\text { investigations reveals numerous } \\
\text { inconsistencies and omissions. } \\
\text { These holes present new } \\
\text { constraints and problems that } \\
\text { require further study. }\end{array}$ \\
\hline $\begin{array}{l}\text { With respect to [13]: } \\
\text { Researchers examined the } \\
\text { effectiveness of Saudi Arabia's } \\
\text { cloud computing in the } \\
\text { education sector, especially in } \\
\text { relation to eLearning. This can } \\
\text { be accomplished by reviewing } \\
\text { a research study survey carried } \\
\text { out in Riyadh, the capital of } \\
\text { Saudi Arabia. }\end{array}$ & $\begin{array}{l}\text { Two inputs have been conducted } \\
\text { and provided Surveys with } \\
\text { the help of a questionnaire for } \\
\text { educators and teachers IT students } \\
\text { in the capital city of Saudi Arabia, } \\
\text { Riyadh. In the cloud computing } \\
\text { background, secondary data has } \\
\text { been obtained from numerous } \\
\text { past study studies. Using } \\
\text { questionnaires from educational } \\
\text { institutions and the IT industry, } \\
\text { primary data was collected }\end{array}$ & $\begin{array}{l}\text { From this comprehensive } \\
\text { analysis of cloud computing } \\
\text { from primary and secondary } \\
\text { information sources and } \\
\text { cloud computing Review } \\
\text { of the answers, we can do } \\
\text { the following Observations } \\
\text { concluding. }\end{array}$ \\
\hline
\end{tabular}


Computing in the Cloud:

a) In learning institutions, it is powerful as it upsurges the Professional ability and knowledge of pupils and students Equips them with the necessities of life today.

b) Improves substantially the level of service offered to customers.

c) Increases budget approximations, predictable approximations Expenses and rapid investment returns.

d) Dramatically lowers costs and makes it possible for institutions to pay only for IT facilities and assets they use in Arabia Saudi.

\section{$4 \quad$ Results and discussion}

\section{A. The Cloud Computing Benefits in Education}

In different ways, cloud computing is certainly advantageous to educational institutions. Below, some of these advantages are shown [17-19]:

a) Economies: Combining cloud computing with education increases its efficiency tremendously by delivering all required IT services to organizations without being paid peruse. This removes the need for frequent hardware and software upgrades, thus alleviating the pressure on institutional budgets.

b) Accessibility: With maximum availability across the year, cloud services are available to everyone, including students and teachers.

c) Diversified learning: As students become more visible to a diversity of instruments' software and related tools in the cloud, the learning environment becomes more complex and effective.

d) Green potential maximization: institutions are empowered to reduce their resource usage to the minimum with cloud computing because it saves the processing power of data centers on the client-side. Consequently, it lowers carbon emissions.

e) user friendly: there is no need to think about the difficulty. It is quick to comprehend and easy to run.

f) Trackability: Do you want to make changes to a lesson and change it again? No trouble. Many updates and iterations of a document can be saved by cloud storage so that you can trace an item's evolution chronologically.

g) Elasticity and Scalability: The demand for computing resources typically exceeds the available resources (supply) in the conventional approach. It could also result in poor quality of service, especially during peak periods of educational operation. The redundant portion of existing resources of cloud computing can meet evolving demands without the need for more IT infrastructure to be supplied.

\section{B. The Cloud Computing Challenges in Education}

While many of the educational cloud computing benefits, like the above, there are also challenges that cannot be ignored. There are some of these challenges [8] [16]: 
a) Data Security: Information security is the most important component of any entity or organization. Cloud information is vulnerable to cloud computing hacking, which includes centralized data storage, especially sensitive data.

b) Vendor Lock-In: The data of educational institutes is vulnerable and huge so it technically and economically becomes difficult to move all resources from one cloud service provider to other. Also, due to variations in software and hardware set ups of different CSPs, it may also result in interoperability issues. In the event that a competitor offers better services, switching to a new cloud provider will be extremely difficult for the business. As a result, interoperability with the cloud is critical for educational establishments. with other educational platforms and to avoid vendor lock-in.

c) Reliability: The system failure occurrence in an organization can be very detrimental to the facilities offered to customers. For instance, in February 2008, there was a three-hour outage on Amazon's S3 and EC2 services. S3 experienced yet another significant outage in July 2008, this time lasting eight hours. In the middle of 2009, Google Gmail went down for three hours, denying 113 million of its users access to their emails and online papers stored as "Google Docs".

d) Compliance issue: Organizations are uncertain of the position of their stored information and who has access to it in a distributed service system where data centers are decentralized all over the world. Cloud service providers have adopted the strategy of setting up data centers within the nation where the organization concerned is domiciled to maintain control of their data. This is because data processed in distant countries could be insecure and vulnerable to hacking.

e) Performance: All the access communications to the cloud is through the internet, adding latency in any contact between the environment and the user.

\section{Guidelines for Using Cloud Computing in Education}

It would be beneficial for organizations wishing to acquire cloud services, for different purposes [20][21][22], to create a list of selection requirements and present them to competing suppliers for their response [23][24][25]

a) Platform: It is important to determine the framework on which the applications are given. Ideally, the software will run the same on all device operating systems and Web browsers, but this is not likely to be the case. It may be critical to advise users to use particular channels. Access to mobile devices is becoming more relevant for many students.

b) Technical issues: Institutions may have to perform such technological integration activities, such as automating the development of a cloud system user account based on data kept in student information systems or enabling a single system-to-system sign-on. It may also be appropriate to monitor use, delete accounts, or execute other systems activities of Management.

c) Functionality: The list should contain the users' necessary features. For instance, in the case of email, this may involve the use of Instead of the web-based applications of a POP client or out of Office notification. The storage of records, issues to consider, can include the total Per-user allocation and the kinds of files that can be allocated Retained. 
d) User experience and accessibility: Some systems can have an overall user experience that is better than others. Usability is key. For example, a need to install other software other than the web browser will make the software less appealing. The usage of disabled people is one concern that needs to be taken into account for ethical and legal reasons. Therefore, companies wishing to implement cloud services should ensure that the software complies with requirements and standards for online accessibility.

\section{Conclusion}

The usage of Cloud Computing among education section in Saudi Arabia is slow and steady. This paper outlines findings from the investigation carried out in regards to education in KSA. We also discussed challenges related with cloud computing especially in the educational sector. Finally, we formulated guidelines to expedite the slow uptake of cloud computing.

\section{References}

[1] Ali. A. (2020). Cloud Computing Adoption at Higher Educational Institutions in the KSA for Sustainable Development. Advanced Computer Science and Applications.11: 196-201. https://doi.org/10.14569/IJACSA.2020.0110352

[2] Hussein, L. A., \& Hilmi, M. F. (2020). Cloud Computing Based E-learning in Malaysian Universities. International Journal of Emerging Technologies in Learning, 15(8). https://doi. org/10.3991/ijet.v15i08.11798

[3] AlFawwaz, B. M. (2017). Effect of Cloud Based Educational Applications in E-learning: Evidence from Jordan. International Journal of Interactive Mobile Technologies, 11(4). https://doi.org/10.3991/ijim.v11i4.6378

[4] Wanotayapitak, S., Saraubon, K., \& Nilsook, P. (2019). Process Design of Cooperative Education Management System by Cloud-based Blockchain E-portfolio. International Journal of Online \& Biomedical Engineering, 15(8). https://doi.org/10.3991/ijoe.v15i08.10374

[5] Quasim, M. T. (2013). An Efficient approach for concurrency control in distributed database system. Indian Streams Research Journal, 3.

[6] Suhaib, M. (2020), Usage of Cloud Computing Technology and Challenges in Japanese Higher Educational Institutes. Scientific \& Technology Research. 9: 2727-2733.

[7] Narwal. M. S, Singh, M. S. P, Singh, M. L., \& Kumar, M. A. (2013), Cloud Computing in Education. National Conference on E-learning and E- learning Technologies (ELETECH India 2013), Hyderabad, Volume: $4^{\text {th }}$ National Conference, June, 2013.

[8] Tavbulatova, Z. Zhigalov, K. Kuznetsova, S. Y., \& Patrusova, A. (2020). Types of cloud deployment. Physics, 1582: 012085. https://doi.org/10.1088/1742-6596/1582/1/012085

[9] Ahmed, I. J. T. (2019). A brief review: security issues in cloud computing and their solutions. Telkomnika, 17: 2812-2817. https://doi.org/10.12928/telkomnika.v17i6.12490

[10] Rashid, A. Chaturvedi, A. (2019). Cloud computing characteristics and services: a brief review. Computer Sciences and Engineering, 7: 421-426. https://doi.org/10.26438/ijcse/ v7i2.421426

[11] Attaran, M., Attaran, S., \& Celik, B. G. (2017). Promises and challenges of cloud computing in higher education: a practical guide for implementation. Higher Education Theory and Practice, 17: 20-38. 
[12] Olaloye, F., Adeyemo, A., Edikan, E., \& Lawal C. O., (2019). Cloud Computing in Education Sector: An Extensive Review, Civil Engineering and Technology (IJCIET), 10: 3158-3171.

[13] AlKhaled, K. A., (2018). Using Google Cloud in Education. Advanced Engineering and Nano Technology (IJAENT) ISSN: 2347-6389, 3: 1-9.

[14] Tashkandi, A., \& Al-Jabri. I. Cloud computing adoption by higher education institutions in Saudi Arabia: Analysis based on TOE, International Conference on Cloud Computing (ICCC), 2015, IEEE, pp. 1-8. https://doi.org/10.1109/CLOUDCOMP.2015.7149634

[15] Singh, U., \& Baheti, P. K. (2017). Role and service of cloud computing for higher education system. International Research Journal of Engineering and Technology (IRJET). 4: 708-709.

[16] Elgelany, A., \& Alghabban, W. G. (2017). Cloud computing: empirical studies in higher education. Advanced Computer Science and Applications, 8: 121-127. https://doi.org/10.14569/ IJACSA.2017.081017

[17] Almutairi, M. M. (2020). A review of cloud computing in education in Saudi Arabia. International Journal of Information Technology, 12: 1385-1391. https://doi.org/10.1007/ s41870-020-00452-6

[18] Saini, L., \& Jyoti, H. K. (2017). Role of cloud computing in education system. International Journal of Advanced Research in Computer Science, 8: 345-347.

[19] Al Rawajbeh, M., Al Hadid, I., \& Al-Zoubi, H. (2019). Adoption of cloud computing in higher education sector: An overview. International Journal of technology and Engineering Studies, 5: 23-29.

[20] Onyema, E. M., Eucheria, N. C., Nneka, U. A., Afriyie, R. K., \& Nwoye, O. U. (2020). Cloud Security Challenges: Implications on Education. International Journal of Computer Science and Mobile Computing, 9: 56-73.

[21] Muhammad, A., Shaikh, A., Naveed, Q. N., \& Qureshi, M. R. N. (2020). Factors affecting academic integrity in E-learning of Saudi Arabian Universities. An investigation using Delphi and AHP. IEEE Access, 8, 16259-16268. https://doi.org/10.1109/ACCESS.2020.2967499

[22] Junaid, M., Shaikh, A., Hassan, M. U., Alghamdi, A., Rajab, K., Al Reshan, M. S., \& Alkinani, M. (2021). Smart Agriculture Cloud Using AI Based Techniques. Energies, 14(16), 5129. https://doi.org/10.3390/en14165129

[23] Bulla, C., Hunshal, B., \& Mehta, S. (2016). Adoption of cloud computing in education system: A survey. International Journal of Engineering Science and Computing, 6: 6375-6380.

[24] Almajalid, R. M. (2017). A survey on the adoption of cloud computing in education sector. International Journal of Computer Trends and Technology, 60: 1-12. https://doi. org/10.14445/22312803/IJCTT-V60P102

[25] Naveed, Q. N., Qureshi, M. R. N., Tairan, N., Mohammad, A., Shaikh, A., Alsayed, A. O., \& Alotaibi, F. M. (2020). Evaluating critical success factors in implementing E-learning system using multi-criteria decision-making. Plos one, 15(5), e0231465. https://doi.org/10.1371/ journal.pone. 0231465

\section{$7 \quad$ Authors}

Gareebah Fahed M Al Rasheedy is a student of Department of Information Technology, College of Computer, Qassim University, Buraydah, Saudi Arabia. E-mail: 421200394@qu.edu.sa.

Dr Nabeel Khan is an Indian Assistant Professor at Department of Information Technology, College of Computer, Qassim University, Buraydah, Saudi Arabia. E-mail: n.khan@qu.edu.sa.

Article submitted 2021-09-05. Resubmitted 2021-10-19. Final acceptance 2021-10-19. Final version published as submitted by the authors. 



iJIM - Vol. 15, No 24, 2021

\section{Imprint}

iJIM - International Journal of Interactive Mobile Technologies

http://www.i-jim.org

Editor-in-Chief

Stamatios Papadakis, University of Crete, Greece

Senior Editor-in-Chief

Thrasyvoulos Tsiatsos, Aristotle University of Thessaloniki, Greece

Executive Editor

Michael E. Auer, CTI Frankfurt/Main - New York - Vienna - Bangalore

Section Editors

Apostolos Gkamas, University Ecclesiastical Academy of Vella, loannina, Greece Micaela Dinis Esteves, Polytechnic Institute of Leiria, Portugal

\section{Technical Editor}

Sebastian Schreiter, Lagorce, France

\section{Editorial Board}

A. Y. Al-Zoubi, Princess Sumaya University for Technology Amman, Jordan Yacob Astatke, Morgan State University, Baltimore, MD, USA

Stephan Böhm, RheinMain University of Applied Sciences, Germany Daphne Economou, University of Westminster, United Kingdom

Juan Antonio Guerrero-Ibáñez, University of Colima, Mexico Hyo-Joo Han, Georgia Gwinnett College, Lawrenceville, GA, USA Markus Feisst, University of Nottingham, UK

Ferial Khaddage, Deakin University, Australia

Kinshuk, Athabasca University, Canada

Adamantios Koumpis, Berner Fachhochschule, Switzerland

Tzu-Chien Liu, National Central University, Taiwan

Hiroaki Ogata, Tokushima University, Japan

Andreas Pester, British University in Egypt, Egypt

Raul Aquino Santos, University of Colima, Mexico

Ana Serrano Tellería, University of Castilla La Mancha, Spain

Doru Ursutiu, University Transilvania of Brasov, Romania

Mudasser Fraz Wyne, National University, Kearny Mesa, CA, USA

\section{Indexing}

International Journal of Interactive Mobile Technologies is indexed in

Elsevier Scopus, INSPEC, Ulrich, DOAJ, EBSCO, Google Scholar, and DBLP

\section{Publication Frequency}

Bimonthly

\section{Publisher}

International Association of Online Engineering (IAOE)

Kirchengasse 10/200

A-1070 WIEN

Austria 